\title{
Evaluation of an Electrolyte Repletion Protocol for Cardiac Surgery Intensive Care Patients
}

\author{
Jodianne Couture, Anne Létourneau, Annie Dubuc, and David Williamson
}

\begin{abstract}
Background: Implementation of electrolyte repletion protocols to facilitate and ensure the safety of electrolyte control is common practice in intensive care units (ICUs). However, few protocols have been evaluated and validated.
\end{abstract}

Objective: To evaluate the effectiveness and safety of an electrolyte repletion protocol in a large, homogeneous group of postoperative patients.

Methods: A retrospective study of patients admitted to the surgical ICU following coronary artery bypass grafting or heart valve replacement was undertaken at the Centre hospitalier universitaire de Sherbrooke, a 682bed tertiary care hospital in Sherbrooke, Quebec. The proportion of measured values for serum potassium concentration that were within the desired range was compared between patients treated according to the electrolyte repletion protocol and those treated with the traditional approach to electrolyte repletion. Management of magnesium, phosphorus, and ionized calcium balance was also compared. The incidence of cardiac arrhythmias was documented, and the safety of the electrolyte repletion protocol was evaluated by determining and comparing proportions of values for serum electrolyte concentration that were above the desired range.

Results: In total, 627 patients were included in the study: 312 in the control group and 315 in the protocol group. The proportion of patients with $100 \%$ of morning values for serum potassium concentration within the normal range was significantly higher in the protocol group than in the control group $(66.1 \%$ versus $56.8 \%$; $p=0.018)$. In the protocol group, significantly more patients received one or more replacement doses of magnesium and phosphorus $(p<0.001)$. The proportions of serum electrolyte values above the normal range were similar between the 2 groups, and there was no difference in the incidence of cardiac arrhythmias.

Conclusions: The electrolyte repletion protocol was more efficacious than traditional electrolyte repletion in maintaining normal serum potassium concentration and was safe.

Key words: electrolytes, protocol, potassium, magnesium, phosphorus, critical care

Can J Hosp Pharm 2013;66(2):96-103

\section{RÉSUMÉ}

Contexte : La mise en place de protocoles de recharge électrolytique favorisant le contrôle prudent des électrolytes est une pratique courante dans les unités de soins intensifs. En revanche, peu de protocoles ont été évalués et validés.

Objectif : Évaluer l'efficacité et l'innocuité d'un protocole de recharge électrolytique dans un important groupe homogène de patients en phase postopératoire.

Méthodes : On a mené une étude rétrospective de patients admis à une unité de soins intensifs chirurgicaux par suite d'un pontage aortocoronarien ou d'un remplacement d'une valvule cardiaque au Centre hospitalier universitaire de Sherbrooke, un centre de soins tertiaires de 682 lits à Sherbrooke, au Québec. On a comparé la proportion des valeurs mesurées pour le taux sérique de potassium qui étaient dans la plage des valeurs désirées chez les patients traités selon le protocole de recharge électrolytique à celle chez ceux traités selon la méthode de remplacement électrolytique classique. On a également comparé la prise en charge de l'équilibre en magnésium, en phosphore et en calcium ionisé. On a constaté l'incidence des arythmies cardiaques et on a évalué l'innocuité du protocole de recharge électrolytique en déterminant et en comparant les proportions des valeurs du taux sérique d'électrolyte qui étaient au-dessus de la plage des valeurs désirées.

Résultats : En tout, 627 patients ont été admis à l'étude : 312 dans le groupe témoin et 315 dans le groupe protocole. La proportion de patients dont $100 \%$ des valeurs du taux sérique de potassium le matin étaient dans la plage des valeurs normales était significativement plus élevée dans le groupe protocole que dans le groupe témoin (66,1\% contre 56,8\%; $p=0,018)$. Dans le groupe protocole, un nombre significativement plus élevé de patients on reçu une ou plusieurs doses de replacement de magnésium et de phosphore $(p<0,001)$. Les proportions de taux sériques d'électrolytes au-dessus de la plage des valeurs normales étaient similaires dans les deux groupes et on n'a observé aucune différence dans l'incidence des arythmies cardiaques.

Conclusions : Le protocole de recharge électrolytique était plus efficace que la méthode de remplacement électrolytique classique pour maintenir un taux sérique normal de potassium et s'est révélé sûr.

Mots clés : électrolytes, protocole, potassium, magnésium, phosphore, soins intensifs

[Traduction par l'éditeur] 


\section{INTRODUCTION}

$\mathrm{E}^{\mathrm{l}}$ lectrolyte disorders frequently occur after cardiac surgery., Hypokalemia has been reported in $34 \%$ of patients, hypomagnesemia in $46 \%$, hypophosphatemia in $83 \%$, and hypocalcemia in $7.8 \% .^{1}$ Electrolyte abnormalities have been associated with complications such as hemodynamic instability and cardiac arrhythmias. ${ }^{3-9}$ Other complications include seizures and tetany, as well as impairment of diaphragmatic contractility. ${ }^{4-6,10}$ Conversely, correction of electrolyte abnormalities in critically ill patients has been shown to reduce complications. For instance, correction of intraoperative hypomagnesemia in cardiac surgery patients undergoing extracorporeal circulation can reduce the incidence of ventricular tachyarrhythmia. ${ }^{10}$

In the intensive care setting, the use of protocols has been shown to enhance patient care in various types of treatment, such as mechanical ventilation and sedation. ${ }^{11,12}$ With regard to electrolyte repletion, numerous studies have focused on the control of a single electrolyte. ${ }^{13-16}$ To date, 4 studies have evaluated repletion protocols for multiple electrolytes in various intensive care settings. ${ }^{17-20}$ The results of these studies have suggested that use of repletion protocols is more effective than standard approaches to electrolyte repletion. ${ }^{18-20}$ However, these studies have been limited by small sample sizes and important between-group differences in clinical characteristics that may have biased the results. The objective of the current study was to evaluate the efficacy and safety of an electrolyte repletion protocol in a large homogenous group of postoperative cardiac surgery patients.

\section{METHODS}

This retrospective study was conducted in the surgical intensive care unit (ICU) at the Centre hospitalier universitaire de Sherbrooke, a 682-bed tertiary care university hospital in Sherbrooke, Quebec. Until the end of 2006, electrolyte repletion for ICU patients was performed by medical staff during rounds or during patient visits. In January 2007, an electrolyte repletion protocol was implemented (see Appendix 1, available at www.cjhp-online.ca/index.php/cjhp/issue/view/ 92/showToc).

To reduce the risk of bias, the current study focused on patients who underwent cardiac surgery, a homogenous group for whom postoperative care did not change after implementation of the protocol. Patients aged 18 years or older who were admitted to the surgical ICU following surgery for coronary artery bypass grafting or heart valve replacement between November 2005 and October 2006 (control group) and between April 2007 and March 2008 (protocol group) were eligible for inclusion. Patients from each group were selected for inclusion by means of an online random-number generator (www.random.org). Patients requiring renal replacement therapy, those with a diagnosis of diabetic ketoacidosis, those weighing less than $45 \mathrm{~kg}$, and those who died during surgery or during the ICU stay were excluded. For patients with multiple ICU admissions during the study period, only the first admission was considered. During the 2-year study period, the medical staff was stable, with no new ICU attending physicians or cardiac surgeons added to the team. Data concerning factors that might contribute to electrolyte changes (i.e., medications, serum $\mathrm{pH}$, transfusion requirements, duration of extracorporeal circulation, parenteral nutrition, oral electrolyte repletion, renal function classified by the RIFLE criteria [risk, injury, failure, loss, and end-stage renal disease],,$^{21}$ and selected concurrent medical conditions such as sepsis and pancreatitis) were collected.

The protocol was developed as a preprinted order sheet with predetermined IV replacement doses that varied according to plasma electrolyte concentrations. The protocol also suggested standard electrolyte monitoring, with specific recommendations regarding the timing of monitoring in relation to administration of replacement doses $(6 \mathrm{~h}$ after potassium repletion and $24 \mathrm{~h}$ after magnesium, phosphate, or calcium repletion). The physician had the option of choosing which electrolyte would be replaced in the case of a low value (potassium, magnesium, phosphate, or calcium) during the ICU stay. Bedside nurses were responsible for following the protocol and for preparing and administering the electrolyte replacement doses.

The primary objective was to evaluate the efficacy of the electrolyte repletion protocol by comparing the proportion of measured values of serum potassium concentration within the desired range before and after implementation of the protocol. Potassium was chosen for the primary end point because it is the electrolyte for which repletion is most often performed in the ICU, and potassium abnormalities are associated with worse outcomes than occur with abnormalities of other electrolytes. Secondary end points included proportion of serum concentration values within the desired range for magnesium, phosphorus, and ionized calcium. Morning serum concentration was chosen as a proxy for daily serum concentrations within the desired range because morning values were systematically available for all patients, and their measurement was not affected by implementation of the protocol. Samples were drawn and electrolyte concentrations measured by the hospital's laboratory according to the same methods throughout the study. The desired serum concentrations were defined as follows: potassium between 3.6 and $5.0 \mathrm{mmol} / \mathrm{L}$, magnesium between 1.62 and $2 \mathrm{mEq} / \mathrm{L}$ (i.e., 0.81 and $1.00 \mathrm{mmol} / \mathrm{L}$ ), phosphorus between 2.79 and $4.49 \mathrm{mg} / \mathrm{dL}$ (i.e., 0.90 and $1.45 \mathrm{mmol} / \mathrm{L}$ ), and ionized calcium (the standard for calcium monitoring in this ICU) between 1.00 and 1.32 
$\mathrm{mmol} / \mathrm{L}$. The incidence of cardiac arrhythmias (atrial fibrillation, cardiac arrest, ventricular fibrillation, ventricular tachycardia, or torsades de pointe) during the hospital stay (ICU and ward) was also compared. Adherence to monitoring guidelines set out in the protocol was evaluated by documenting the proportion of serum potassium concentration measurements ordered within $6 \pm 2 \mathrm{~h}$ after repletion, as required by the electrolyte protocol. The safety of the protocol was evaluated by comparing the mean proportion of morning serum electrolyte concentration values above the desired range and the proportion of calcium-phosphate product values greater than $2.2 \mathrm{mmol}^{2} \backslash \mathrm{L}^{2}$. Calcium-phosphate product values above $2.2 \mathrm{mmol}^{2} \backslash \mathrm{L}^{2}$ have been associated with an increased risk of vascular, valvular, and renal calcification. ${ }^{22}$

For some patients included in the protocol group, the standard electrolyte order sheet was not used, even though they were treated after implementation of the protocol. Therefore, we first analyzed data for all patients included for this period and then analyzed data for the subgroup of patients who received care according to the protocol (per-protocol group).

The sample size calculation was based on an initial analysis of serum potassium concentration for 92 patients who had undergone cardiac surgery and were admitted to the ICU between April and August 2006. It was determined that a sample size of 250 patients per group was needed to show a $7.5 \%$ difference in the mean proportion of daily morning serum potassium values in the established target range, given an $\alpha$ error of $5 \%$ and a $\beta$ error of $80 \%$. Normally distributed, continuous descriptive variables are presented as mean and standard deviation, and values were compared between groups with the Student $t$ test. For data that were not normally distributed, descriptive variables are presented with median and interquartile range (25th to 75 th percentile), and values were compared between groups with the Mann-Whitney $U$ test. Dichotomous variables and the proportions of daily electrolyte concentration values within the target range are presented as frequencies and percentages and were compared with the $\chi^{2}$ test (or Fisher exact test if the frequency was less than 5). Multivariate logistic regression was used to evaluate independent factors associated with optimal potassium control, defined as $100 \%$ of the morning serum potassium concentration values within the desired range. SPSS version 18.0 (IBM, Armonk, New York) was used for all statistical analysis, and nQuery 6.0 (Statistical Solutions, Cork, Ireland) was used for sample size calculation. The ethics committee for health research in humans of the Centre hospitalier universitaire de Sherbrooke and Université de Sherbrooke approved the study.

\section{RESULTS}

For the 2 study periods, a total of 710 patients were eligible for inclusion, and 325 patients were selected from each period. After application of the exclusion criteria, 312 patients remained in the control group and 315 in the protocol group. Patients were excluded because of continuous renal replacement therapy (11 control patients and 9 patients in the protocol group) and death during surgery ( 2 control patients and 1 patient in the protocol group). The baseline characteristics of the 2 groups were similar (Table 1). In both groups, coronary artery bypass grafting was the main indication for surgery, and the majority of patients underwent extracorporeal circulation. The duration of cardiopulmonary bypass was longer in the control group than in the protocol group (135 versus $124 \mathrm{~min}$ ). The use of angiotensin-converting enzyme inhibitors or angiotensin II receptor blockers was more frequent in the control group than in the protocol group $(29.2 \%$ versus $20.3 \%)$; the same was true for thiazide diuretics $(2.9 \%$ versus $0.3 \%)$ and corticosteroids (10.3\% versus $5.7 \%)$. Conversely, vasopressors $(95.2 \%$ versus $85.3 \%)$ and insulin $(100 \%$ versus 96.5\%) were used more often in the protocol group. All other clinical variables and medications were well balanced between groups.

The proportion of morning serum potassium values within the desired range was not significantly different between the control and protocol groups (Table 2). However, the protocol group had more patients with $100 \%$ of the morning potassium values within the desired range $(66.1 \%$ versus $56.8 \%, p=0.018)$. In addition, the per-protocol analysis showed a significantly higher proportion of morning potassium values within the desired range in the protocol group $(p<0.001)$. Significantly more of the patients in the protocol group than in the control group received one or more repletion doses of magnesium or phosphate $(p<0.001)$ (Figure 1). More patients in the control group than in the per-protocol subgroup received calcium repletion $(p<0.001)$. There was no difference between the control and protocol groups in the incidence of atrial fibrillation ( $43.9 \%$ versus $45.4 \%)$ and flutter $(7.1 \%$ versus $5.1 \%)$. Similarly, there were no differences in the incidence of other arrhythmias (cardiac arrest, $1.3 \%$ versus $0.9 \%$; ventricular fibrillation, $0.3 \%$ versus $1.9 \%$; and torsades de pointes, $0.6 \%$ versus $0.3 \%$ ).

In the multivariate analysis, use of the electrolyte repletion protocol was independently associated with optimal maintenance of serum potassium concentration within the desired range in both the all-patient analysis (odds ratio [OR] 1.57, 95\% confidence interval $[\mathrm{CI}] 1.03-2.37 ; p=0.034)$ and the per-protocol analysis (OR 2.36, 95\% CI 1.49-3.74; $p<0.001)$. The other predictor of optimal potassium control in the all-patient analysis was stable renal function (OR 3.59, 95\% CI 1.80-7.15; $p<0.001$ ) (Table 3). Female sex (OR 0.32, $95 \%$ CI $0.20-0.52 ; p<0.001)$ and use of angiotensin-converting enzyme inhibitors or angiotensin II receptor blockers (OR 0.45, 95\% CI 0.28-0.73; $p=0.001$ ), corticosteroids (OR 0.33, 
Table 1. Baseline Characteristics of Patients in the Cardiac Surgery Intensive Care Unit

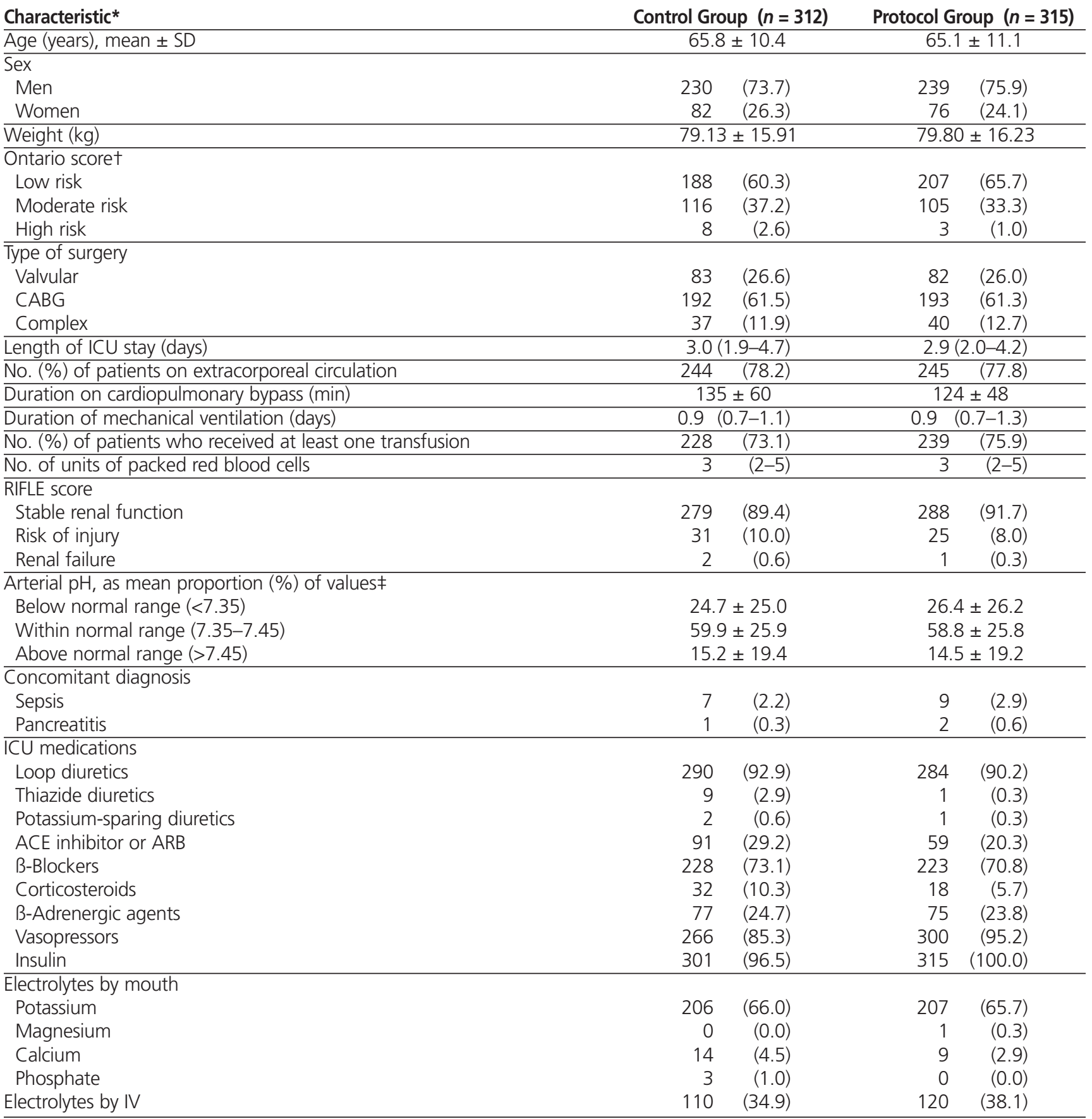

$\overline{\mathrm{ACE}}=$ angiotensin-converting enzyme, $\mathrm{ARB}=$ angiotensin II receptor blocker, $\mathrm{CABG}=$ coronary artery bypass graft, $\mathrm{ICU}=$ intensive care unit.

*Continuous variables are presented as mean \pm standard deviation (for normally distributed data) or as median and interquartile range. Categorical variables are presented as frequencies and percentages.

TThe Ontario Score is a 6-variable risk index (age, sex, left ventricular function, type of surgery, urgency of surgery, and repeat operation) used to predict mortality as well as ICU and postoperative stay among patients who undergo cardiac surgery. ${ }^{23}$ fProportions of arterial pH values above, below, and within normal range were calculated for each patient, and the means of proportions per group were then calculated. 
Table 2. Proportion of Morning Electrolyte Values within Normal Range

\begin{tabular}{|c|c|c|c|c|c|c|c|c|}
\hline \multirow{2}{*}{ Proportion (\%) } & \multicolumn{6}{|c|}{ Group; No. (\%) of Patients* } & \multicolumn{2}{|c|}{ Comparison and $p$ Value } \\
\hline & \multicolumn{2}{|c|}{ Control Group } & \multicolumn{2}{|c|}{ Protocol Group } & \multicolumn{2}{|c|}{$\begin{array}{l}\text { Per-Protocol } \\
\text { Group }\end{array}$} & \multirow[t]{2}{*}{$\begin{array}{l}\text { Control v. } \\
\text { Protocol }\end{array}$} & \multirow[t]{2}{*}{$\begin{array}{c}\text { Control v. } \\
\text { Per-Protocol }\end{array}$} \\
\hline \multirow{2}{*}{\multicolumn{9}{|c|}{$\begin{array}{l}\text { Within normal range } \\
\text { Potassium }\end{array}$}} \\
\hline & & & & & & & & \\
\hline $0-24$ & 16 & $(5.2)$ & 9 & (2.9) & 12 & (4.9) & 0.06 & $<0.001$ \\
\hline $25-49$ & 15 & $(4.9)$ & 15 & (4.9) & 9 & (3.7) & & \\
\hline 50-74 & 67 & $(21.8)$ & 61 & (19.9) & 39 & $(16.0)$ & & \\
\hline 75-99 & 35 & (11.4) & 19 & $(6.2)$ & 7 & (2.9) & & \\
\hline$<100$ & 133 & $(43.2)$ & 104 & (33.9) & 67 & $(27.5)$ & 0.018 & $<0.001$ \\
\hline 100 & 175 & $(56.8)$ & 203 & $(66.1)$ & 177 & $(72.5)$ & & \\
\hline Magnesium & & & & & & & 0.37 & 0.45 \\
\hline $0-24$ & 79 & (26.2) & 67 & (22.0) & 66 & $(27.0)$ & & \\
\hline $25-49$ & 34 & (11.3) & 32 & $(10.5)$ & & $(7.4)$ & & \\
\hline $50-74$ & 73 & (24.2) & 95 & (31.1) & 69 & (28.3) & & \\
\hline 75-99 & 14 & $(4.6)$ & 11 & (3.6) & 8 & (3.3) & & \\
\hline 100 & 102 & (33.8) & 100 & (32.8) & 83 & $(34.0)$ & & \\
\hline Phosphate & & & & & & & 0.47 & 0.53 \\
\hline $0-24$ & 37 & $(31.9)$ & 54 & (27.3) & 33 & (22.8) & & \\
\hline $25-49$ & 9 & $(7.8)$ & 15 & $(7.6)$ & 14 & $(9.7)$ & & \\
\hline $50-74$ & 20 & (17.2) & 43 & (21.7) & 31 & (21.4) & & \\
\hline 75-99 & 2 & $(1.7)$ & 10 & $(5.1)$ & 4 & $(2.8)$ & & \\
\hline 100 & 48 & (41.4) & 76 & (38.4) & 63 & $(43.4)$ & & \\
\hline Ionized calcium & & & & & & & 0.44 & 0.62 \\
\hline $0-24$ & 4 & (1.4) & 3 & (1.0) & & $(0.9)$ & & \\
\hline $25-49$ & 1 & $(0.3)$ & 3 & $(1.0)$ & 0 & $(0.0)$ & & \\
\hline $50-74$ & 7 & (2.4) & 8 & $(2.7)$ & 9 & $(4.2)$ & & \\
\hline 75-99 & 6 & $(2.1)$ & 13 & (4.5) & 7 & (3.3) & & \\
\hline 100 & 271 & $(93.8)$ & 267 & $(91.8)$ & 197 & (91.6) & & \\
\hline \multicolumn{9}{|l|}{ Above normal } \\
\hline Potassium & & & & & & & 0.16 & 0.043 \\
\hline 0 & 291 & $(94.5)$ & 299 & (97.4) & 240 & $(98.4)$ & & \\
\hline $1-25$ & 9 & (2.9) & 3 & $(1.0)$ & 1 & $(0.4)$ & & \\
\hline$>25$ & 8 & $(2.6)$ & 5 & (1.6) & 3 & $(1.2)$ & & \\
\hline Magnesium & & & & & & & 0.57 & 0.94 \\
\hline 0 & 248 & (82.1) & 240 & (78.7) & 199 & (81.6) & & \\
\hline $1-25$ & 16 & $(5.3)$ & 19 & $(6.2)$ & 12 & $(4.9)$ & & \\
\hline$>25$ & 38 & (12.6) & 46 & (15.1) & 33 & (13.5) & & \\
\hline Phosphate & & & & & & & 0.78 & 0.77 \\
\hline 0 & 99 & (85.3) & 164 & (82.8) & 127 & (87.6) & & \\
\hline $1-25$ & 4 & (3.4) & 10 & (5.1) & 6 & (4.1) & & \\
\hline$>25$ & 13 & $(11.2)$ & 24 & (12.1) & 12 & $(8.3)$ & & \\
\hline Ionized calcium & & & & & & & 0.75 & 0.67 \\
\hline 0 & 288 & (99.7) & 290 & (99.7) & 214 & (99.5) & & \\
\hline $1-25$ & 0 & $(0.0)$ & 1 & $(0.3)$ & 1 & $(0.5)$ & & \\
\hline$>25$ & 1 & $(0.3)$ & 0 & $(0.0)$ & 0 & $(0.0)$ & & \\
\hline
\end{tabular}

*Some patients did not have electrolyte concentration measured every day.

95\% CI $0.15-0.74 ; p=0.007$ ), and vasopressors (OR 0.28, $95 \%$ CI $0.11-0.69 ; p=0.006)$ were associated with poor potassium control.

The safety analysis showed a lower but nonsignificant proportion of calcium-phosphate product greater than 2.2 $\mathrm{mmol}^{2} \backslash \mathrm{L}^{2}$ in the protocol group than in the control group $(1.26 \%$ versus $5.43 \% ; p=0.30)$. In addition, there was a significantly greater proportion of serum potassium values above the desired range in the control group than in the per-protocol group (Table 2). Adherence with the protocol after implementation was good, with potassium replacement being prescribed for 273 (86.6\%) of the patients, magnesium replacement for 272 (86.3\%), phosphorus replacement for 246 (78.1\%), and calcium replacement for 245 (77.8\%). In the protocol group, monitoring of serum potassium concentration following a supplemental dose within $6 \pm 2$ hours, as suggested by the protocol, was performed in $49.6 \%$ (228/460) of cases. 


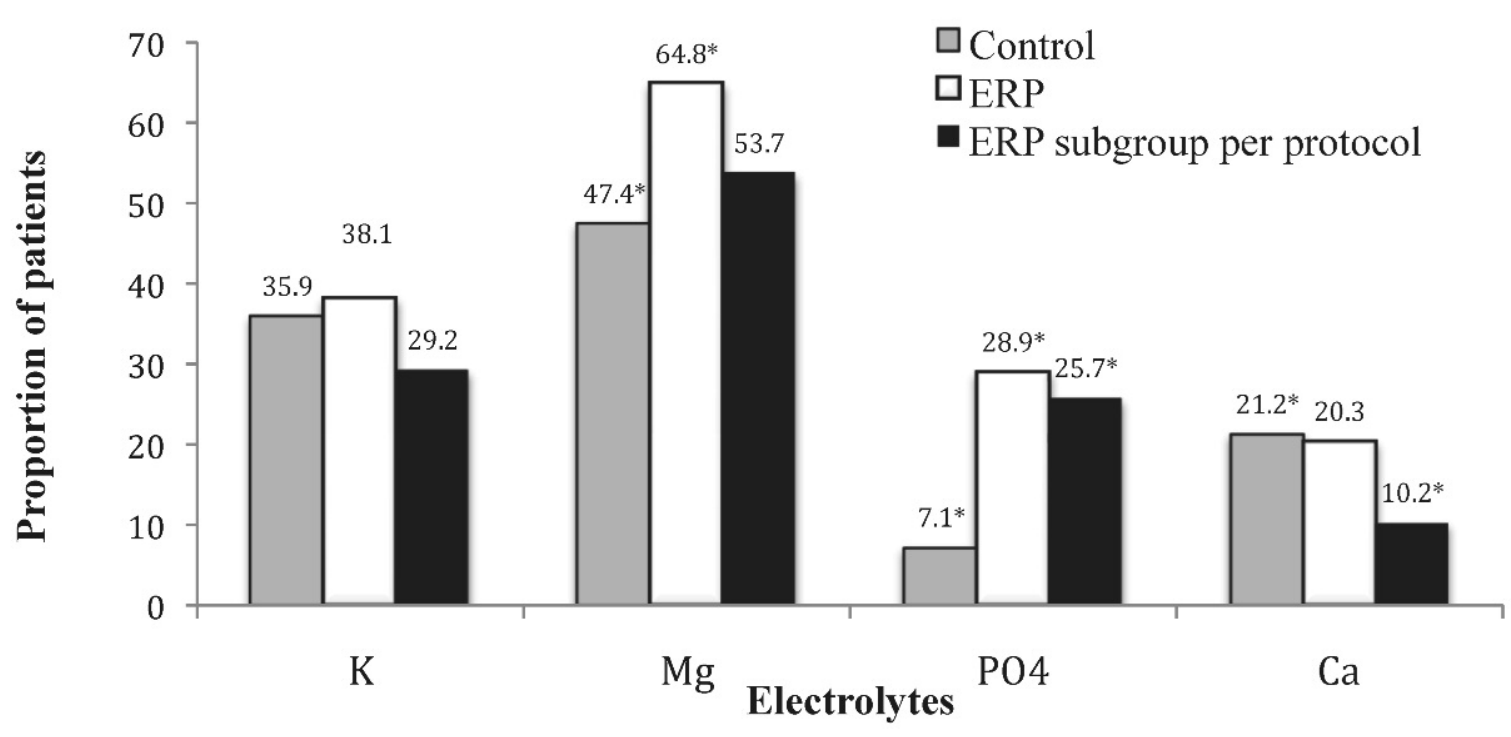

Figure 1. Proportion of patients (\%) who received one or more repletion doses of potassium, magnesium, phosphate, or calcium. Asterisks indicate statistically significant differences $(p<0.001)$, as follows: magnesium (control versus protocol), phosphate (control versus protocol, control versus per-protocol subgroup), calcium (control versus per-protocol subgroup). $\mathrm{ERP}=$ electrolyte repletion protocol.

Table 3. Multivariate Analysis of Factors Associated with Optimal Potassium Control (All Patients)

\begin{tabular}{|c|c|c|c|}
\hline Factor & \multicolumn{2}{|c|}{ OR (95\% Cl) } & $p$ value \\
\hline Electrolyte repletion protocol & 1.57 & $(1.03-2.37)$ & 0.034 \\
\hline Duration of extracorporeal circulation (min) & 1.00 & $(1.00-1.01)$ & 0.82 \\
\hline ACE inhibitor or ARB & 0.45 & $(0.28-0.73)$ & 0.001 \\
\hline Corticosteroids & 0.33 & $(0.15-0.74)$ & 0.007 \\
\hline Vasopressors & 0.28 & $(0.11-0.69)$ & 0.006 \\
\hline Insulin & 0.41 & $(0.04-3.67)$ & 0.42 \\
\hline Age & 0.99 & $(0.97-1.01)$ & 0.48 \\
\hline Sex (female v. male) & 0.32 & $(0.20-0.52)$ & $<0.001$ \\
\hline Stable RIFLE & 3.59 & $(1.80-7.15)$ & $<0.001$ \\
\hline \multicolumn{4}{|l|}{ Type of surgery } \\
\hline CABG (reference) & 1.00 & & 0.22 \\
\hline Valvular v. CABG & 0.84 & $(0.49-1.42)$ & 0.51 \\
\hline Complex v. CABG & 0.51 & $(0.24-1.10)$ & 0.09 \\
\hline \multicolumn{4}{|l|}{ Ontario score* } \\
\hline Low risk (reference) & 1.00 & & \\
\hline Moderate and high risk v. low risk & 0.79 & $(0.45-1.39)$ & 0.42 \\
\hline
\end{tabular}

\section{DISCUSSION}

Patients undergoing cardiac surgical procedures are at high risk for electrolyte depletion. Hypothermia during surgery and extracorporeal circulation induce cellular shifts and increased urinary excretion of electrolytes, which are responsible for this phenomenon. ${ }^{1}$ The effectiveness and safety of protocols to optimize electrolyte management and facilitate the care of critically ill patients have been demonstrated in only a limited number of studies. ${ }^{17-20}$ The protocol used in the current study hospital was similar to those previously published, but suggested replacement doses of electrolytes were generally higher, and calcium repletion was included. The results of this study showed that this electrolyte repletion protocol was safe and led to better control of daily serum potassium concentration. No differences in the proportions of serum magnesium, phos- 
phorus, and calcium values within the normal range were observed, despite the fact that more patients in the protocol group received magnesium and phosphorus supplementation (Figure 1). One possible explanation for this finding is underdosing. We noticed that, in many cases, a single supplementary dose of the electrolytes, as suggested by the protocol, was insufficient to normalize serum concentrations. Thus, doses of magnesium and phosphorus recommended in the protocol could be increased. From $91.6 \%$ to $93.8 \%$ of patients had morning calcium values within normal range $100 \%$ of the time. As such, calcium repletion could be eliminated from the electrolyte repletion protocol to limit the costs associated with monitoring serum calcium concentration. Finally, follow-up measurement of serum potassium concentration $6 \pm 2 \mathrm{~h}$ after a supplemental dose was performed only $49.6 \%$ of the time. This suboptimal adherence with this aspect of the protocol should be addressed. No conclusions can be drawn concerning the lower trend for calcium-phosphate product in the protocol group, as the clinical implications of this effect are unknown in the acute care setting.

The strengths of this study included the large sample size and the homogeneous patient population. Some clinical variables and medications seemed unbalanced between the groups (Table 1), but the final effect on serum potassium concentration seemed balanced. In addition, we controlled for administration of all other electrolytes. Given that supplementation by other routes was similar between groups, it is unlikely that these electrolytes influenced the results. The study was limited by its retrospective design and the comparison of only daily serum electrolyte concentrations. Although morning sampling does not necessarily reflect the electrolyte concentrations throughout the day, these values were chosen because they were systematically available for all patients and were not affected by implementation of the protocol. Safety analyses were limited to evaluation of serum electrolyte concentrations and arrhythmias. Other adverse events, such as nausea and vomiting, were not evaluated. Finally, the study focused on patients undergoing cardiac surgery, and potential extrapolation of effectiveness and safety to other patient populations is therefore limited.

\section{CONCLUSIONS}

The implementation of protocols in the ICU is increasingly being used to enhance patient care. The electrolyte repletion protocol described here was efficacious in maintaining normal serum potassium concentration. No changes in the control of other electrolytes were observed. The use of this protocol seemed safe, as it did not cause above-normal serum concentration of potassium, magnesium, phosphorus, or calcium. A more aggressive dosing strategy may be warranted to improve the effectiveness of the protocol with regard to magnesium and phosphorus. The necessity of keeping calcium repletion as part of the protocol should be re-evaluated. Finally, education of the nursing staff is required to enhance the measurement of serum electrolyte concentration following potassium repletion.

\section{References}

1. Polderman KH, Girbes AR. Severe electrolyte disorders following cardiac surgery: a prospective controlled observational study. Crit Care. 2004;8(6):R459-66.

2. Cohen J, Kogan A, Sahar G, Lev S, Vidne B, Singer P. Hypophosphatemia following open heart surgery: incidence and consequences. Eur $J$ Cardiothorac Surg. 2004;26(2):306-10.

3. Diercks DB, Shumaik GM, Harrigan RA, Brady WJ, Chan TC. Electrocardiographic manifestations: electrolyte abnormalities. J Emerg Med. 2004;27(2):153-60.

4. Gennari FJ. Hypokalemia. N Engl J Med. 1998;339:451-8.

5. Sedlacek M, Schoolwerth AC, Remillard BD. Electrolyte disturbances in the intensive care unit. Semin Dial. 2006;19(6):496-501.

6. Tong GM, Rude RK. Magnesium deficiency in critical illness. J Intensive Care Med. 2005;20(1):3-17.

7. Soliman HM, Mercan D, Lobo SS, Mélot C, Vincent JL. Development of ionized hypomagnesemia is associated with higher mortality rates. Crit Care Med. 2003;31(4):1082-7.

8. Kraft MD, Btaiche IF, Sacks GS, Kudsk KA. Treatment of electrolyte disorders in adult patients in the intensive care unit. Am J Health Syst Pharm. 2005;62(16):1663-82.

9. Wahr JA, Parks R, Boisvert D, Comunale M, Fabian J, Ramsay J, et al. Preoperative serum potassium levels and perioperative outcomes in cardiac surgery patients. Multicenter Study of Perioperative Ischemia Research Group. JAMA. 1999;281(23):2203-10.

10. Wilkes NJ, Mallett SV, Peachey T, Di Salvo C, Walesby R. Correction of ionized plasma magnesium during cardiopulmonary bypass reduces the risk of postoperative cardiac arrhythmia. Anesth Analg. 2002;95(4):828-34.

11. Meade MO, Ely EW. Protocols to improve the care of critically ill pediatric and adult patients. JAMA. 2002;288(20):2601-3.

12. Bucknall TK, Manias E, Presneill JJ. A randomized trial of protocoldirected sedation management for mechanical ventilation in an Australian intensive care unit. Crit Care Med. 2008;36(5):1444-50.

13. Charron T, Bernard F, Skrobik Y, Simoneau N, Gagnon N, Leblanc M. Intravenous phosphate in the intensive care unit: more aggressive repletion regimens for moderate and severe hypophosphatemia. Intensive Care Med. 2003;29(8):1273-8.

14. Perreault MM, Ostrop NJ, Tierney MG. Efficacy and safety of intravenous phosphate replacement in critically ill patients. Ann Pharmacother. 1997;31(6):683-8.

15. Dickerson RN, Morgan LM, Croce MA, Minard G, Brown RO. Treatment of moderate to severe acute hypocalcemia in critically ill trauma patients. JPEN J Parenter Enteral Nutr. 2007;31(2):228-33.

16. Hoekstra M, Vogelzang M, Drost JT, Janse M, Loef BG, van der Horst IC, et al. Implementation and evaluation of a nurse-centered computerized potassium regulation protocol in the intensive care unit--a before and after analysis. BMC Med Inform Decis Mak. 2010;10:5.

17. Hijazi M, Al-Ansari M. Protocol-driven vs. physician-driven electrolyte replacement in adult critically ill patients. Ann Saudi Med. 2005;25(2): $105-10$.

18. Kanji Z, Jung K. Evaluation of an electrolyte replacement protocol in an adult intensive care unit: a retrospective before and after analysis. Intensive Crit Care Nurs. 2009;25(4):181-9.

19. Owen P, Monahan MF, MacLaren R. Implementing and assessing an evidence-based electrolyte dosing order form in the medical ICU. Intensive Crit Care Nurs. 2008;24(1):8-19.

20. Todd SR, Sucher JF, Moore LJ, Turner KL, Hall JB, Moore FA. A multidisciplinary protocol improves electrolyte replacement and its effectiveness. Am J Surg. 2009;198(6):911-5.

21. Bellomo R, Ronco C, Kellum JA, Mehta RL, Palevsky P; Acute Dialysis Quality Initiative workgroup. Acute renal failure-definition, outcome measures, animal models, fluid therapy and information technology needs: the Second International Consensus Conference of the Acute Dialysis Quality Initiative (ADQI) Group. Crit Care. 2004;8(4):R204-12. 
22. Tertti R, Harmoinen A, Leskinen Y, Metsärinne KP, Saha H. Comparison of calcium phosphate product values using measurement of plasma total calcium and serum ionized calcium. Hemodial Int. 2007;11(4):411-6.

23. Tu JV, Jaglal SB, Naylor CD. Multicenter validation of a risk index for mortality, intensive care unit stay, and overall hospital length of stay after cardiac surgery. Circulation. 1995;91(3):677-84.

Jodianne Couture, BPharm, MSc, is a Pharmacist in the Pharmacy Department, Centre hospitalier universitaire de Sherbrooke, Hôpital Fleurimont, Sherbrooke, Quebec

Anne Létourneau, BPharm, MSc, is Pharmacist in the Pharmacy Department, Hôpital du Haut-Richelieu, Saint-Jean-sur-Richelieu, Quebec.

Annie Dubuc, BPharm, MSc, is a Pharmacist in the Pharmacy Department, Centre hospitalier universitaire de Sherbrooke, Hôpital Fleurimont, Sherbrooke, Quebec
David Williamson, MSc(Pharm), BCPS, is a Clinical Associate Professor, Faculté de pharmacie, Université de Montréal, and a Critical Care Pharmacist, Hôpital du Sacré-Coeur de Montréal, Montréal, Quebec.

Competing interests: None declared.

Address correspondence to:

David Williamson

Hôpital du Sacré-Coeur de Montréal

5400, boulevard Gouin Ouest

Montréal QC H4J 1C5

e-mail: david.williamson@umontreal.ca

\section{Acknowledgements}

We thank Julie Perron, BPharm, MSc, Hugues Blain, BPharm, MSc, and Benoît Cossette, BPharm, MSc, for helping with conception of the study. We also thank Vincent Nault, BSc, Sbire, for information technology services; Nathalie Carrier, MSc, for assistance with statistical analyses; and Laurie Kister, pharmacy student, and Nathalie Simard, pharmacy technician, for data collection. Société canadienne des pharmaciens d'hôpitaux

\section{Membership Year 2012/2013 (July 1, 2012 - June 30, 2013)}

Are you a current member of the Canadian Society of Hospital Pharmacists?

CSHP has celebrated 65 years of inspiration and leadership among a rapidly growing network of over 3000 pharmacy colleagues. As a member of CSHP, you will have access to resources and opportunities that will enhance your career and help impact the direction of healthcare in Canada. Your participation in CSHP 2015, an initiative challenging all pharmacists to improve patient medication outcomes and safety through advancing pharmacy practice excellence by the year 2015, is a prime example.

For more information about CSHP, please visit us at www.cshp.ca. We invite you to reap the benefits of an affordable membership with CSHP.

Membership Enquiries: Please contact Membership Services

Bus.: (613) 736-9733 Ext. 222 Fax: (613) 736-5660 Email: membershipservices@cshp.ca 